one-month period without medication. This reduction, however, was apparent in the controls as well as in the patients receiving the drugs and was obvious in both laboratories.

\section{Discussion}

Reports of the chromosome-breaking potential of various drugs have evoked much concern, with particular attention paid to those psychotropic compounds (including hallucinogens) reportedly having this capability. Nonetheless, relatively few well-controlled in-vivo prospective studies have been performed to investigate these properties. In the present investigation an attempt was made to obtain baseline values of chromosome damage in the subjects before the actual investigation began. An additional feature of this double-blind study was the simultaneous culturing and scoring of replicate samples from each subject in two independent cytogenetic laboratories. The results were completely negative for both drugs tested and there was no statistically significant difference between the laboratories for any value scored. The method of culturing, harvesting, and scoring of the cells was similar although not identical in both laboratories, and therefore results tested the repeatability and reliability of such procedures.

Our negative findings indicate that neither perphenazine nor chlorpromazine has chromosome-breakage potential. This is in contrast to the findings of Nielsen et al. (1969), which indicated that perphenazine could perhaps induce chromosome damage. That study, however, contained several possible biases. Firstly, no systematic attempt was made to obtain baseline values of chromosome damage in the subjects studied. More importantly, those patients receiving perphenazine also received orphenadrine. The chromosome-breaking potential of orphenadrine was not examined, yet Nielsen et al. attributed the positive effect seen to perphenazine, not considering any possible effects of orphenadrine or a synergism between the two agents administered. Orphenadrine was not studied in the present experiment since its administration was not clinically justifiable. The lack of chromosome damage induced by perphenazine, however, suggests that orphenadrine may have been the active agent in the studies of Nielsen et al. (1969). On the other hand the present studies confirmed the previous negative studies of others concerning chlorpromazine. Cohen et al. (1969) studied this drug in vitro and in vivo with negative results, as did Sandberg in a double-blind study of 35 schizophrenic patients (personal communication). Therefore none of the psychotropic drugs tested for the induction of cytogenetic damage has clearly shown such potential.

These studies were supported in part by grants from the Department of Health Education and Welfare, Maternal and Child Health Service (project No. 417), and the U.S. Public Health Service (MH-05101). We wish to thank Dr. A. Sugarman, New Jersey Psychiatric Institute, Princeton, New Jersey, for allowing the study of patients under his care and for supplying blood specimens, Mr. M. Miller, Schering Corporation, for statistical analysis, and Dr. P. Reyes, Mrs. C. Lockwood, and Mrs. V. Wolff for technical help.

\section{References}

Cohen, M. M., Hirschhorn, K., and Frosch, W. A. (1967). New England fournal of Medicine, 277, 1043

Cohen, M. M., Hirschhorn, K., and Frosch, W. A. (1969). Fournal of the American Medical Association, 207, 2425.

Moorhead, P. S., Nowell, P. C., Mellman, W. J., Battips, D. M., and Hungerford, D. A. (1960). Experimental Cell Research, 20, 613.

Nielsen, J., Friedrich, U., and Tsuboi, T. (1969). British Medical fournal 3, 634 .

Schmid, W., and Staiger, G. R. (1969). Mutation Research, 7, 99.

Schmid, W., and Staiger, G. R. (1969). Mutation

Stenchever, M. A., and Frankel, R. B. (1969). American fournal of Obstetrics and Gynecology, 103, 836 .

\title{
Clinical Evaluation of Co-trimoxazole and Furazolidone in Treatment of Shigellosis in Children
}

\author{
UDOM LEXOMBOON, PETHAI MANSUWAN, CHIRAPHUN DUANGMANI, PANYASRI BENJADOL \\ M. TALMAGE M'CMINN
}

British Medical fournal, 1972, 3, 23-26

\begin{abstract}
Summary
Co-trimoxazole (trimethoprim-sulphamethoxazole) was compared with furazolidone in the treatment of shigellosis in two groups of 33 and 30 patients respectively. Those treated with co-trimoxazole recovered more quickly; none had shigellae in the faeces four days after the start of treatment, whereas in the group given furazolidone eight still had positive stool cultures seven days after treatment.

The susceptibility of 104 shigella strains to seven antimicrobial agents was studied by plate dilution
\end{abstract}

Children's Hospital, Bangkok, Thailand

UDOM LEXOMBOON, M.B., PH.D., Senior Staff

PETHAI MANSUWAN, M.B., Director

Department of Bacteriology and Mycology, S.E.A.T.O. Medical Research Laboratory, Bangkok, Thailand

CHIRAPHUN DUANGMANI, M.B., Medical Research Specialist

PANYASRI BENIADOL, M.S., Medical Research Technologist

M. TALMAGE M'CMINN, C.P.T., M.S.C., Chief of Department technique. All agents but tetracycline and chloramphenicol were found highly effective against most of the strains tested. All shigella isolates were resistant to sulphamethoxazole, and $63 \%$ were sensitive to trimethoprim. Potentiation of trimethoprim by sulphamethoxazole was shown in that all strains tested became sensitive to the combination of trimethoprim and sulphamethoxazole in a ratio of $1: 20$.

\section{Introduction}

Shigella spp. are the most common bacterial pathogens isolated from diarrhoeal children in many countries (Ramos-Alvarez and Olarte, 1964; Goodwin et al., 1967; Lexomboon and Sunakorn, 1968-9). In a recent study conducted by us at the Children's Hospital, Bangkok, shigella bacilli were found to be the most frequent cause of gastroenteritis in 588 children, with the isolation rate of $20 \%$ (Lexomboon and Sunakorn, 1968-9). Patients with clinical gastroenteritis due to shigellae should be given specific antimicrobial therapy, since several studies have indicated that effective antibiotic treatment rapidly rids the 
patients intestine of shigella organisms and decreases the manifestations of clinical illness (Riley, 1968; Poovichit, et al., 1966).

The sulphonamides were once the most extensively used antimicrobial agents in the treatment of shigellosis. Nevertheless, sulphonamide-resistant strains of shigellae have been reported (Garfinkel et al., 1953; Marberg et al., 1958; Turk, 1960), and this drug is no longer used in the treatment of this disease. Resistance of Shigella spp. to tetracycline and chloramphenicol, which are the other commonly used drugs, has also increased, and neither of them are now used in the treatment of shigellosis. Ampicillin has been claimed to be a safe and highly effective drug and has often been used as the drug of choice in shigella diarrhoea (Haltalin et al., 1957). Nevertheless, a significant proportion of shigella strains have been found resistant to ampicillin (Beargie and Riley, 1963).

It is apparent that a search for new antimicrobial agents in the treatment of shigellosis is necessary. Co-trimoxazole (trimethoprim-sulphamethoxazole) has been found to be very effective in growth inhibition of most shigella strains in vitro (Lexomboon, unpublished data), and some recent studies have claimed its therapeutic value in the treatment of the disease (Felix et al., 1971; Freiberg, 1971; Titze, 1971). Shigella isolates have also been found to be highly sensitive to furazolidone in vitro (Noyes et al., 1969). The use of furazolidone in some hospitals is based on the in-vitro sensitivities of many shigella isolates to the drug, but the effectiveness of this has never been proved.

The purpose of this study was to compare co-trimoxazole (Bactrim) with furazolidone in the treatment of shigellosis in children. Particular reference is made to therapeutic efficacy, both clinically and bacteriologically, and also to tolerance of both drugs.

\section{Materials and Methods}

Patients in this study visited the outpatient clinic of the Children's Hospital, Bangkok, from March to August 1971 with the clinical symptoms of acute gastroenteritis. They were assigned at random to be treated with either furazolidone or co-trimoxazole. Before specific therapy was started rectal swabs were obtained and immediately inoculated on to MacConkey and S.S. agar plates and also into selenite-F broth. Suspect isolates from these media were further identified biochemically and serologically.

Antimicrobial therapy was started without awaiting the results of stool cultures. Patients were withdrawn from the study if their stool cultures did not confirm the diagnosis of shigellosis. Clinical evaluation of the disease and also rectal swab cultures were made on alternate days for seven days.

The treatment schedules were oral co-trimoxazole or furazolidone syrup. Co-trimoxazole was given either in syrup form (paediatric syrup, $5 \mathrm{ml}$ of syrup containing $40 \mathrm{mg}$ trimethoprim and $200 \mathrm{mg}$ sulphamethoxazole) or as paediatric tablets $(20 \mathrm{mg}$ trimethoprim and $100 \mathrm{mg}$ sulphamethoxazole), the dosage being adjusted according to age (under 2 years $1 / 2$ teaspoonful twice a day; 2-5 years 1 or 2 tablets twice a day, and 6-12 years 2 or 4 tablets twice daily). Furazolidone was given at a dosage of $15-20 \mathrm{mg} / \mathrm{kg} /$ day in four divided doses.

Minimum inhibitory concentrations were determined by a plate dilution method. Six antimicrobial agents-tetracycline, chloramphenicol, neomycin, colistin, ampicillin, and furazolidone-were incorporated into Mueller-Hinton agar medium to give twofold differences between adjacent plates in the series. Trimethoprim and sulphamethoxazole were tested separately and in a combination of $1: 20$ respectively. The inoculum size was about $10^{6}$ organisms in tryptic soy broth.

A total of 166 patients with gastroenteritis were available for this study. Shigella spp. were isolated from $78(46.9 \%)$ of these patients. Eight patients were found to harbour both Shigella spp. and enteropathogenic Escherichia coli or Salmonella spp, and these patients were excluded from the study. Sixty-three shigellosis patients completed the three scheduled visits and were used for analysis. Thirty-three were treated with cotrimoxazole and 30 were treated with furazolidone. These patients are characterized in terms of age, sex, duration of illness before therapy, and serotypes of shigellae isolated in Tables I and II.

TABLE I-Analysis of Patients Studied

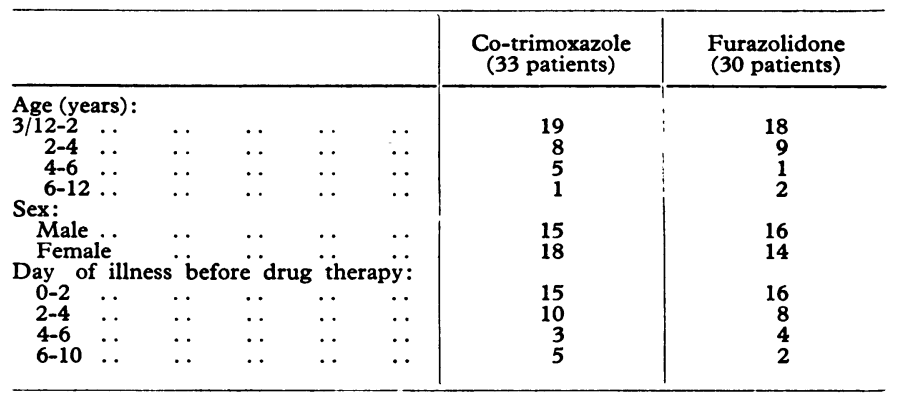

TABLE II-Shigella Serotypes Isolated from Patients' Stools

\begin{tabular}{|c|c|c|c|c|c|}
\hline \multicolumn{4}{|c|}{ Organism } & \multirow{2}{*}{$\begin{array}{c}\begin{array}{c}\text { Co-trimoxazole } \\
\text { Group }\end{array} \\
9 \\
18 \\
1 \\
5 \\
-\end{array}$} & \multirow{2}{*}{$\begin{array}{c}\begin{array}{c}\text { Furazolidone } \\
\text { Group }\end{array} \\
4 \\
12 \\
3 \\
10 \\
1\end{array}$} \\
\hline $\begin{array}{l}\text { Shigella flexneri-2 } \\
\text { Shigella flexneri-3 } \\
\text { Shigella flexneri-4 } \\
\text { Shigella sonnei form } 1 \\
\text { Shigella boydii-1 }\end{array}$ & $\begin{array}{l}\ldots \\
\cdots \\
\cdots\end{array}$ & $\begin{array}{l}\ldots \\
\cdots \\
\cdots \\
\cdots\end{array}$ & $\begin{array}{l}\cdots \\
\cdots \\
\cdots\end{array}$ & & \\
\hline Total & .. & .. & .. & 33 & 30 \\
\hline
\end{tabular}

The study groups were comparable in regard to the following characteristics. About $58 \%$ of the children were under 2 years of age and most of them were seen within a few days after the onset of the disease. Shigella flexneri was the most frequent isolate $(74 \cdot 6 \%)$. This finding differs from those reported from the United States, the United Kingdom, France, and Japan (Reller, 1971; Gillies, 1964; Azturm-Rubinsten, 1968; Aoki, 1969), where Shigella sonnei was the most prevalent serotype isolated.

\section{Results}

The 104 strains of shigellae used for the in-vitro study included those isolated from the patients studied and also from stool specimens sent to the laboratory from other sources during the period under review. All these strains were tested against eight antimicrobial agents. The proportions of susceptible strains of shigellae to seven antimicrobial agents at a minimum inhibitory concentration of $12.5 \mu \mathrm{g} / \mathrm{ml}$ or less are shown in the Chart. All isolates were sensitive to furazolidone and colistin, and most of them were sensitive to ampicillin $(91.3 \%)$ and neomycin $(94.2 \%)$. On the other hand, a high percentage was resistant to tetracycline $(84 \%)$ and chloramphenicol $(88 \cdot 5 \%)$.

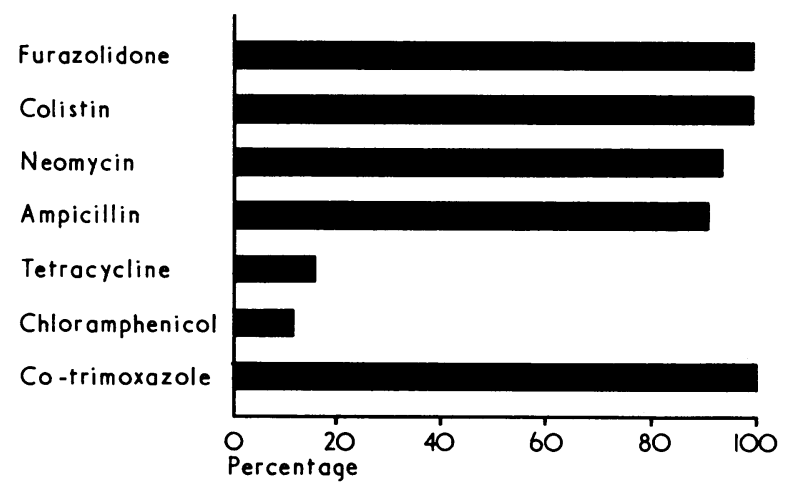

Percentage of susceptibility of 104 shigella isolates. 
Most strains of shigellae (63.3\%) were sensitive to trimethoprim at a concentration of $12.5 \mu \mathrm{g} / \mathrm{ml}$ but all of them were resistant to $500 \mu \mathrm{g} / \mathrm{ml}$ or more of sulphamethoxazole (Tables III and IV). When the combination of trimethoprim and sulphamethoxazole in a ratio of 1:20 was used it was found that all strains of shigellae tested were sensitive to $25 \mu \mathrm{g}$ of trimethroprim per $\mathrm{ml}$ (Table IV).

TABLE III-Minimum Inhibitory Concentration of Suphamethoxazole for 104 Strains of Shigellae

\begin{tabular}{ll|c|c|c|c|c}
\hline & & \multicolumn{2}{|c|}{ Minimum Inhibitory Concentration $(\mu \mathrm{g} / \mathrm{ml})$} \\
\cline { 3 - 5 } & 500 & 1,000 & 2,000 & 4,000 & 8,000 \\
\hline No. of strains &. & 2 & 4 & 10 & 68 & 20 \\
\hline
\end{tabular}

TABLE IV-Minimum Inhibitory Concentration (M.I.C.) of Trimethoprim and Co-trimoxazole for 104 Strains of Shigellae

\begin{tabular}{|c|c|c|c|c|c|}
\hline & \multicolumn{5}{|c|}{ Minimum Inhibitory Concentration $(\mu \mathrm{g} / \mathrm{ml})$} \\
\hline & $0 \cdot 78$ & $1 \cdot 56-3 \cdot 12$ & $6 \cdot 25-12 \cdot 5$ & $25-50$ & $100-200$ \\
\hline $\begin{array}{l}\text { Trimethoprim } \\
\text { Co-trimoxazole* }\end{array}$ & $\begin{array}{l}24 \\
39\end{array}$ & $\begin{array}{l}20 \\
29\end{array}$ & $\begin{array}{l}23 \\
35\end{array}$ & $\begin{array}{r}13 \\
1\end{array}$ & 24 \\
\hline
\end{tabular}

${ }^{*}$ M.I.C. expressed as the concentration of trimethoprim in co-trimoxazole.

The bacteriological responses to the treatment are listed in Table V. Of the 33 children given co-trimoxazole 22 had no shigella bacilli in their stools after 48 hours of treatment and all 33 patients had negative shigella stool cultures after four days of treatment. Ten of the 30 patients in the furazolidone group had negative shigella stool cultures at the end of 48 hours, and eight patients still had positive shigella stool cultures after seven days. The mean number of days until the stool culture became negative for shigellae was 2.4 in the co-trimoxazole group and 3.9 in the furazolidone group.

Response to treatment was interpreted either as clinically improved or as having failed. Clinically improved indicated a patient having no fever and regaining a well-formed stool without blood or mucus. The number of stools a day became fewer than three. By using these criteria 31 of the 33 patients in the co-trimoxazole group were regarded as clinically improved within 48 hours, and all of them were improved within four days after therapy. Thirteen of the 30 patients in the furazolidone group were clinically improved after 48 hours of therapy. Seven failed to respond to the medication and showed little or no sign of improvement at the end of seven days (Table VI).

The bacteriological and clinical results showed that after one, two, three, four, and seven days of treatment co-trimoxazole was superior to furazolidone regarding duration of the good

TABLE v-Bacteriological Response to Antimicrobial Therapy in 63 Shigellosis Patients

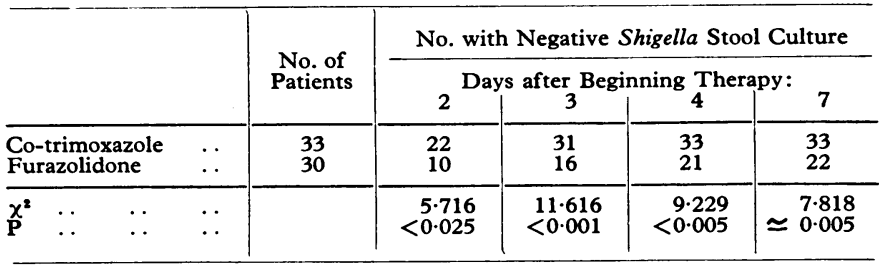

TABLE VI-Clinical Response to Antimicrobial Therapy in 63 Shigellosis Patients

\begin{tabular}{|c|c|c|c|c|c|c|}
\hline & & \multirow{2}{*}{$\begin{array}{l}\text { No. of } \\
\text { Patients }\end{array}$} & \multicolumn{4}{|c|}{ No. Clinically Improved } \\
\hline & & & \multicolumn{4}{|c|}{ Days after Beginning Therapy: } \\
\hline $\begin{array}{l}\text { Co-trimoxazole } \\
\text { Furazolidone }\end{array}$ & $\because$ & $\begin{array}{l}33 \\
30\end{array}$ & $\begin{array}{r}15 \\
4\end{array}$ & $\begin{array}{l}31 \\
13\end{array}$ & $\begin{array}{l}32 \\
18\end{array}$ & $\begin{array}{l}33 \\
23\end{array}$ \\
\hline $\begin{array}{ll}\chi^{2} & \ldots \\
\end{array}$ & .. & & $\begin{array}{r}6.248 \\
<0.02\end{array}$ & $\begin{array}{r}16.778 \\
<0.001\end{array}$ & $\begin{array}{r}10.954 \\
<0.001\end{array}$ & $\begin{array}{l}6.461 \\
<0.01\end{array}$ \\
\hline
\end{tabular}

bacteriological response in stools as well as of the clinical cure. The high significance of these findings was proved by a statistical evaluation performed according to the $\chi^{2}$ test (see Tables $\mathrm{V}$ VI). Patients who after the seventh day of therapy still had positive stool cultures were classified as having definitely failed.

There were no adverse drug reactions in any patients studied except in one patient receiving co-trimoxazole, who developed maculopapular rash on the second day of drug administration. This rash disappeared within 48 hours without treatment.

\section{Discussion}

The clinical illness of shigella infection may vary from mild and self-limiting to severe and fatal. In most cases symptoms generally decrease spontaneously in three to seven days (Garfinkel et al., 1953). For this reason it has been difficult to evaluate the results of specific therapy on the clinical disease. Generally a well controlled, double-blind technique is required in such a study. Our study programme, however, did not include a placebo control group because the patients were treated at an outpatient clinic and might not have returned for subsequent examination or treatment. The results of this study, however, indicate that co-trimoxazole is not only efficacious from a bacteriological standpoint but that it statistically significantly reduces the duration of clinical illness when compared with furazolidone.

Since furazolidone is poorly absorbed from the gastrointestinal tract a higher rate of both bacteriological and clinical failures was to be expected. The poor response to non-absorbable antimicrobial agents in shigellosis patients may be due to the fact that shigella bacilli have the ability to invade the submucosa of the intestine during the course of the illness (Labrec et al., 1964), so that the antimicrobial agents are unable to act on the intracellular micro-organisms.

The in-vitro study indicated that most but not all of the isolates were sensitive to trimethoprim. Nevertheless, when sulphonamide was added it was possible to show the potentiation of trimethoprim by sulphamethoxazole.

The results of our in-vitro tests suggest that tetracycline and chloramphenicol should seldom if ever be given to shigellosis patients. Ampicillin is the only absorbable antimicrobial agent among the other highly effective agents such as furazolidone, colistin, and neomycin and it is considered to be the most useful drug in the treatment of shigellosis. The in-vitro susceptibilities of 104 shigella strains showed that $8.7 \%$ of them were resistant to ampicillin. When considering the wide use of ampicillin in this community, where antimicrobials are available without prescription, it is believed that a sharp increase in the number of ampicillin-resistant shigella strains might be expected. In this regard it will be extremely important to watch the sensitivity pattern of shigella bacilli and to look for a new agent such as co-trimoxazole for the treatment of this disease.

\section{References}

Aoki, Y. (1969). Tropical Medicine, 11, 45.

Azturm-Rubinsten, S. (1968). Archivum Immunologiae et Therapiae Experimentalis, 16, 421 .

Beargie, R. A., and Riley, H. D., jun. (1963). In Antimicrobial Agents and Chemotherapy, p. 331. Ann Arbor, American Society for Microbiology.

Felix, H., Mora, M., Castets, M., Duval, J., and Lafaix, Ch. (1971). Presented at the ViI International Congress on Chemotherapy, Prague.

Freiberg, T. (1971). Arzneimittel-Forschung, 21, 599.

Garfinkel, B. T., et al. (1953). Journal of the American Medical Association, 151,1157 .

Gillies, R. R. (1964). Journal of Hygiene, 62, 1.

Goodwin, M. H., Love, G. I., Mackel, D. C., Berquist, K. R., and Ganelin, R. S. (1967). American fournal of Tropical Medicine and Hygiene, 16, 178. Haltalin, K. C., Nelson, J. D., Ring, R., Sladoje, M., and Hinton, L. V. (1967). Fournal of Pediatrics, R0, R.,

Labrec, E. Ho., Schneider, H., Magnani, T. J., and Formal, S. B. (1964). fournal of Bacteriology, 88, 1503.

Lexomboon, U., and Sunakorn, P. (1968-9). Collected Papers of Women's and Children's Hospital, 1, 62 . 
Marberg, K., Altmann, G., and Eshkol-Bruck, A. (1958). American fournal of Tropical Medicine and Hygiene, 7, 51 .

Noyes, H. E., Benjadol, Panyasri, and Taylor, R. L. (1969). Fournal of the Medical Association of Thailand, 52, 115.

Poovichit, B., Lexomboon, U., and Susilvorn, P. (1966). Fournal of the Department of Medical Service, 15, 557 .
Ramos-Alvarez, M., and Olarte, J. (1964). American fournal of Diseases of Children, 107, 218.

Reller, L. B. (1971). Applied Microbiology, 21, 21.

Riley, H. D., jun. (1968). Pediatric Clinics of North America, 15, 22.

Titze, W. (1971). Arzneimittel-Forschung, 21, 597.

Turk, D. C. (1960). Lancet, 2, 460 .

\title{
Withdrawal Depression in Obese Patients after Fenfluramine Treatment
}

\author{
JUDITH M. STEEL, MARION BRIGGS
}

British Medical fournal, 1972, 3, 26-27

\section{Summary}

Measurements of subjective feeling in 20 patients receiving fenfluramine alternating with placebo and in 19 patients receiving phentermine alternating with placebo indicated that depression of mood occurred four days after fenfluramine withdrawal but no such depression was seen with phentermine.

\section{Introduction}

All the common anorexic agents in current use are amphetamine cogeners having in common the phenylethylamine structure illustrated in the following examples:

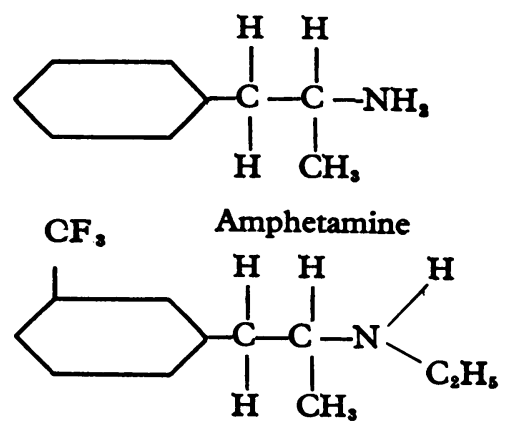

Fenfluramine

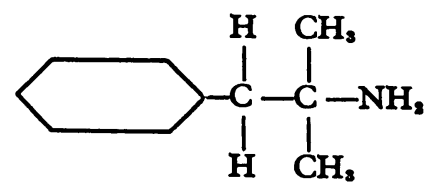

Phentermine

As many anorexic agents have some of the stimulant properties of amphetamine there has been considerable anxiety about their possible exploitation as drugs of abuse (Duncan and Munro, 1968; Advisory Committee Report, 1970). It is sometimes implied that if no side effects are stimulated by the central nervous system the drug will be free from this hazard. Such an assumption may be unwarranted, since addiction to barbitur-

Diabetic and Dietetic Department, Royal Infirmary, Edinburgh JUDITH M. STEEL, M.B., M.R.C.P., Research Registrar

Department of Psychiatry, University of Edinburgh, Royal Edinburgh Hospital

MARION BRIGGS, B.sc., Research Assistant ates and tranquillizers is well documented (Isbell, 1950) and compound preparations containing both an amphetamine and a barbiturate-for example, Drinamyl-are commonly used "drugs of abuse."

Fenfluramine is the most widely prescribed non-stimulant amphetamine derivative in this country. It has mild sedative properties and, with the exception of one unconfirmed report, has not been recognized as a drug of abuse (Brandon, 1969; Hawks, 1970) and has been successfully used to prevent withdrawal symptoms in patients dependent on methylamphetamine and dexamphetamine (Jones, 1971). However, Oswald et al. (1971) recorded consistent changes in mood after withdrawal of fenfluramine from patients who had taken it for the preceding 28 days or longer, depression being maximal on the fourth post-withdrawal day. Adverse or unpleasant effects on withdrawal indicate that the organism has become adapted to the drug in a manner which may lead to physical or psychological dependence on it.

The present study was undertaken to compare the effects on mood and appetite of fenfluramine and phentermine. The latter agent, having mild stimulatory effects, has been suspected of being taken for "kicks" (Duncan and Munro, 1968) though there are no confirmed reports of its abuse in this country (Advisory Committee's Report, 1970). A case has been reported from Ireland of a patient abusing several amphetamine-like drugs including phentermine (Murray, 1964) and another single case from the United States (Rubin, 1964).

\section{Design of Study}

The patients were obese women aged 20 to 60 years who were participating in a double-blind controlled trial of fenfluramine and phentermine in varying regimens as aids to weight reduction. Details of this trial will be reported elsewhere. Participants were asked to make a record, each evening, of their mood and subjective appetite during that day, using the linear self-rating record sheet described by Oswald et al. (1971) and discussed by Aitken (1969). At the end of the trial the records of two comparable groups of patients were analysed in detail. The first group consisted of 20 patients who received fenfluramine $20 \mathrm{mg}$ thrice daily for 28 days followed by placebo for 28 days. The second comprised 19 patients who took phentermine $30 \mathrm{mg}$ (as a slow-release resin preparation Duromine) each morning plus identical placebo tablets at midday and in the evening for 28 days, followed by placebo alone for 28 days.

\section{Results}

The mean ratings of mood and of appetite for the two groups over the whole 56-day period are shown in Figs. 1-4. It is clear that both agents were effective as appetite suppressants as compared with placebo. Neither caused any marked shift of mood 